\title{
Pengaruh Word Of Mouth dan Brand Awareness terhadap
}

\section{Keputusan Pembelian Xing Fu Tang di Indonesia}

\author{
Jessica Tee, Rezi Erdiansyah, Sisca Aulia \\ jessicatee30@gmail.com,rezie@fikom.untar.ac.id, siscaa@fikom.untar.ac.id \\ Fakultas Ilmu Komunikasi Tarumanagara
}

\begin{abstract}
Along with the development of the times, food and drinks also develop with new innovations and new brands that have their own characteristics. The existence of a new brand is intended to attract consumers by making purchasing decisions. In this research, researchers want to know how much the influence of word of mouth and brand awareness so that purchasing decisions occur. Researchers are interested in drinks with a new innovation, the bubble tea brand Xing Fu Tang in Indonesia. Researchers took consumer samples of Xing Fu Tang by using Google forms with a total of 120 respondents in three branches namely Lippo Mall Puri, Lippo Mall Kemang, and Pluit Village. Data analysis was performed by researchers using statistical product and service solutions (SPSS) version 15 and Lisrel 8.70 software as software from the Structural Equation Model (SEM). SEM in this study is used to determine the extent of the influence of word of mouth and brand awareness on purchasing decisions. The results of this study indicate that word of mouth significantly influences the purchase decision with a t-value of 2.11 and brand awareness influences the purchase decision with a $t$-value of 2.38. With these results, entrepreneurs especially bubble tea drinks need to increase word of mouth and brand awareness to increase consumer purchases.
\end{abstract}

Keywords: brand awareness, purchase decisions, word of mouth

\begin{abstract}
Abstrak
Seiring berkembangnya zaman, makanan dan minuman juga ikut berkembang dengan adanya inovasi baru dan adanya merek baru yang memiliki ciri khas tersendiri. Dengan adanya merek baru dimaksudkan untuk menarik konsumen dengan melakukan keputusan pembelian. Pada penelitian ini, peneliti ingin mengetahui seberapa besar pengaruh word of mouth dan brand awareness sehingga terjadinya keputusan pembelian. Peneliti tertarik dengan minuman dengan inovasi baru yaitu bubble tea merek Xing Fu Tang di Indonesia. Peneliti mengambil sampel konsumen Xing Fu Tang dengan menggunakan google form dengan total 120 responden di tiga cabang yaitu Lippo Mall Puri, Lippo Mall Kemang, dan Pluit Village. Analisis data yang dilakukan dengan menggunakan program statistical product and service solutions (SPSS) versi 15 dan software Lisrel 8.70 sebagai piranti lunak dari Structural Equation Model (SEM). SEM dalam penelitian ini digunakan untuk mengetahui sejauh mana pengaruh word of mouth dan brand awareness terhadap keputusan pembelian. Hasil penelitian ini menunjukkan bahwa word of mouth berpengaruh terhadap keputusan pembelian dengan nilai t-value sebesar 2.11 dan brand awareness berpengaruh terhadap keputusan pembelian dengan nilai t-value sebesar 2.38. Dengan hasil tersebut, para pengusaha khususnya minuman bubble tea perlu meningkatkan word of mouth dan brand awareness untuk meningkatkan pembelian dari konsumen.
\end{abstract}

Kata kunci: brand awareness, purchase decisions, word of mouth 


\section{Pendahuluan}

Tindakan yang dilakukan oleh konsumen untuk memilih atau tidaknya suatu barang atau jasa untuk dibeli akan menjadi sebuah keputusan pembelian (Kotler, 2002). Sehingga bisa diartikan bahwa, pengambilan keputusan pembelian terjadi bila konsumen memilih salah satu dari banyaknya pilihan yang ada dalam penyelesaian masalah jika adanya tindakan membeli.

Tentunya keputusan pembelian dipengaruhi banyak faktor yang seperti yang dikemukakan Nugraha (2015) di penelitiannya mengenai keputusan pembelian pada Cafe Roti Gempol dan Kopi Anjis yang dipengaruhi oleh word of mouth. Penelitian tersebut diketahui word of mouth secara berpengaruh terhadap keputusan pembelian. Adapun penelitian lainnya yang dilakukan oleh Billy H (2017) bahwa keputusan pembelian sepatu Nike dipengaruhi oleh brand awareness dan brand image memiliki pengaruh. Dalam penelitian yang dilakukan ini, peneliti tertarik untuk meneliti mengenai keputusan pembelian dengan variabel word of mouth dan brand awareness yang mempengaruhinya.

Dalam persaingan bisnis, banyak cara pemasaran yang dilakukan perusahaan untuk tercapainya keputusan pembelian. Pada penelitian Kiki (2018), ia mengemukakan bahwa proses word of mouth merupakan cara pemasaran yang paling efektif dan efisien karena hal tersebut dapat dengan mudah menyebar secara luas, cepat dan dipercaya oleh calon-calon konsumen. Menurut Kotler dan Amstrong (2001), paling efektif sebuah sumber jika berasal dari keluarga, teman, ataupun tetangga. Bisa dikatakan sumber-sumber yang didapat itu merupakan word of mouth dengan rekomendasi yang terjadi di suatu lingkungan mengenai suatu produk yang mempengaruhi adanya suatu keputusan pembelian.

Adapun hal yang juga mempengaruhi keputusan pembelian ialah brand awarenes. Rasa percaya diri akan meningkat jika konsumen tersebut sadar dan merek tersebut ada dalam puncak pikirannya dalam keputusan pembelian oleh konsumen. Hal tersebut dapat memperkecil masalah setelah membeli yang disarankan pada suatu merek yang diputuskan untuk dibeli (Aaker dalam Suprapti, 2010). Sadarnya akan merupakan kemampuan yang dimiliki konsumen dalam mengidentifikasi sebuah merek dan seberapa ingat akan merek (Kotler dan Keller, 2012).

Pada tahun 2019 ini banyak inovasi baru mengenai makanan dan minuman salah satunya adalah produk minuman bubble tea. Banyak merek yang terus meluncurkan produknya dengan ciri khas masing-masing untuk memikat konsumen. Salah satunya adalah Xing Fu Tang yang dibuka pertama kali di Lippo Mall Puri. Menurut detik.com, untuk membeli minuman yang dijual oleh Xing Fu Tang, setiap orang harus meluangkan waktunya selama 2 jam untuk mengantre (https://m.detik.com/food/resto-dan-kafe/d-4592367/xing-fu-tang-antre-2-jam-untukcicipi-brown-sugar-boba-milk. Diakses pada 24 September 2019).

Oleh karena itu, peneliti mengangkat topik ini karena sesuai dengan pengalaman peneliti yang merasa adanya dampak dari word of mouth di lingkungan sekitar yang membuat adanya keputusan pembelian. Peneliti juga ingin mengetahui seberapa besar masyarakat sadar akan adanya merek baru Xing Fu Tang yang membuat keputusan pembelian Xing Fu Tang.

\section{Word of Mouth}

Menurut Sernovitz (2009), percakapan yang baik atau positif merupakan hasil dari word of mouth. Sebelum mereka memutuskan untuk membeli atau mengkonsumsinya, orang cenderung bertanya pada yang lainnya terlebih dahulu dan 
akan mempengaruhi keputusan yang dipilih. Godes and Mayzlin (2004) mengemukakan dua elemen word of mouth, yaitu volume dan dispersion. Volume dapat diartikan sebagai frekuensi yaitu seberapa banyak atau seringnya seseorang berbicara dan merekomendasikannya. Banyaknya percakapan tentunya berpengaruh pada seberapa banyak orang yang mengetahui mengenai hal yang dibicarakan. Dispersion merupakan pada tingkat sebuah percakapan baik produk atau jasa mengambil tempat pada komunikasi yang luas seperti keluarga, sahabat, teman dan lain sebagainya.

\section{Brand Awareness}

Jika seseorang atau calon konsumen untuk mampu mengenal dan mengingat adanya merek yang merupakan bagian dari sebuah golongan dalam produk tertentu maka hal tersebut merupakan ciri dari seseorang sadar akan sebuah merek (Aaker, dalam Rangkuti, 2009). Menurut Priansa (2017) merek terdiri dari atas empat tingkatan berbeda yang menjadi indikator dalam penelitian ini yaitu sadar akan merek (unware brand), mengenali suatu merek (brand recognition), mengingat merek (brand recall), dan puncak pikiran (top of mind).

\section{Keputusan Pembelian}

Saat konsumen telah menentukan pilihannya dari banyak pilihan dan melakukan pembelian barang atau jasa, maka keputusan pembelian pun terjadi. Pengambilan keputusan dilakukan oleh konsumen diawali karena adanya kesadaran atas keinginan dan kebutuhan. Keputusan terdiri dari lima tahapan (Kotler dan Keller, 2009), yaitu dimulai dari adanya pengenalan suatu masalah, pencarian informasi sebagai jalan keluar, mengevaluasi alternatif yang ada, menentukan pilihan dengan keputusan pembelian, serta adanya perilaku pasca pembelian.

\section{Hipotesis}

$\mathrm{H}_{1}$ : Word of Mouth memiliki pengaruh yang signifikan terhadap keputusan pembelian.

$\mathrm{H}_{2}$ : Brand Awareness memiliki pengaruh yang signifikan terhadap keputusan pembelian.

\section{Metode Penelitian}

Metode kuantitatif dilakukan adalah metode yang digunakan pada penelitian ini. Metode penelitian kuantitatif digunakan untuk meneliti populasi atau sampel tertentu (Sugiyono (2016). Cara pengambilan sampel dilakukan secara sampling insidental dimana peneliti bertemu sampel secara insiden atau kebetulan, jika peneliti merasa orang tersebut cocok maka orang tersebut akan dijadikan sampel.

Penelitian ini memiliki 24 indikator pernyataan yang diolah sesuai dengan dimensi yang membentuk masing-masing variabel.penelitian ini memiliki tiga variabel, yang pertama adalah word of mouth yang di dalamnya terdapat 4 indikator dalam membentuk dimensinya. Selanjutnya brand awareness memiliki 8 indikator yang membentuk dimensinya. Variabel terakhir yaitu keputusan pembelian yang di dalamnya terdapat 12 indikator yang membentuknya.

Teknik kuesioner (angket) adalah teknik pengolahan data yang digunakan dengan memberikan pertanyaan-pertanyaan pada responden secara langsung (Sugiyono 2016). Dalam pengukuran di penelitian ini menggunakan skala likert. Skala 
Likert digunakan untuk sekelompok orang yang ditetapkan oleh peneliti secara spesifik dan disebut sebagai variabel penelitian. Menurut Sugiyono (2016) Variabel yang diukur dengan skala likert dijabarkan menjadi indikator variabel dan dijadikan untuk menyusun item-item berupa pertanyaan atau pernyataan. Responden akan diberikan lima pilihan sebagai jawaban sesuai yang ada pada skala likert yaitu: Sangat Setuju (SS), Setuju (S), Netral (N), Tidak Setuju (TS), dan Sangat Tidak Setuju (STS). Kuesioner ini akan penulis sebarkan kepada responden yaitu para pembeli Xing $\mathrm{Fu}$ Tang di Indonesia, penulis akan menyebarkan kuesioner secara langsung melalui google form kepada para pembeli di ketiga cabang Xing $\mathrm{Fu}$ Tang di Indonesia sebanyak 120 responden.

Program statistical product and service solutions (SPSS) versi 15 dan software Lisrel 8.70 yaitu Structural Equation Model (SEM) merupakan teknik pengolahan data yang digunakan dalam penelitian ini sebagai alat bantu.

\section{Hasil Temuan dan Diskusi}

Dalam penelitian yang dilakukan, penulis menyebarkan kuesioner kepada 120 responden konsumen minuman Xing Fu Tang. Berdasarkan jenis kelamin, jumlah responden perempuan dalam penelitian ini yaitu 67 orang $(55,8 \%)$ dan sebanyak 53 orang $(44,2 \%)$ responden laki-laki. Dari hasil tersebut bisa dikatakan bahwa responden perempuan memiliki jumlah lebih banyak. Berdasarkan usia, responden paling banyak dalam penelitian merupakan responden yang berusia 21 sampai 30 tahun sebanyak 67 orang $(55,8 \%)$. Yang kedua adalah sebanyak 27 orang $(22,5 \%)$ responden berusia kurang dari 20 tahun. Ketiga adalah sebanyak 19 orang $(15,8 \%)$ responden berusia 31 sampai 40 tahun. Keempat adalah sebanyak 7 orang $(5,8 \%)$ responden berusia lebih dari 40 tahun. Berdasarkan pekerjaan, profesi responden sebagai pelajar atau mahasiswa memiliki jumlah yang paling banyak sebesar 50 orang $(41,7 \%)$. Kedua adalah sebanyak 38 orang $(31,7 \%)$ responden yang berprofesi karyawan. Ketiga adalah responden sebanyak 17 orang (14,2\%) yang berprofesi sebagai yang lainya. Dan yang keempat adalah adalah responden sebanyak 15 orang (12,5\%) yang berprofesi sebagai wirausaha. berdasarkan tempat pembelian Xing Fu Tang di Lippo Mall Puri, Lippo Mall Kemang dan Pluit Village memiliki jumlah yang sama sebanyak 40 orang $(33,3 \%)$.

\section{Model Pengukuran}

Uji validitas yang digunakan ini memiliki tujuan untuk mengukur valid atau sah butir-butir pertanyaan pada kuesioner yang ada. Jika pertanyaan atau kuesioner mampu mengungkap suatu yang diukur oleh kuesioner maka kuesioner dapat dikatakan valid. Menurut Nisfiannoor (2013), untuk menilai apakah butir dalam kuesioner valid atau tidak yaitu apabila nilai angka korelasi atau corrected item total correlation di atas 0.2 maka setiap item pertanyaan dinyatakan valid.

Tabel 1. Uji Validitas

\begin{tabular}{clcc}
\hline Variabel & \multicolumn{1}{c}{ Butir Indikator } & $\begin{array}{c}\text { Corrected } \\
\text { Item Total } \\
\text { Correlation }\end{array}$ & Keterangan \\
\hline & $\begin{array}{l}\text { Saya sering mendengar Xing Fu } \\
\text { Tang dalam percakapan sehari-hari }\end{array}$ & 0.552 & Valid \\
\cline { 2 - 4 } & $\begin{array}{l}\text { Saya sering mendapat rekomendasi } \\
\text { Xing Fu Tang dari orang lain }\end{array}$ & 0.456 & Valid \\
\hline
\end{tabular}




\begin{tabular}{|c|c|c|c|}
\hline \multirow[t]{2}{*}{$\begin{array}{l}\text { Word Of } \\
\text { Mouth }\end{array}$} & $\begin{array}{l}\text { Saya sering mendengar Xing Fu } \\
\text { Tang dibicarakan oleh keluarga, } \\
\text { teman ataupun orang lain }\end{array}$ & 0.471 & Valid \\
\hline & $\begin{array}{l}\text { Saya sering mendengar Xing Fu } \\
\text { Tang dibicarakan oleh orang yang } \\
\text { pernah mencoba ataupun akan } \\
\text { mencobanya. }\end{array}$ & 0.463 & Valid \\
\hline \multirow{8}{*}{$\begin{array}{l}\text { Brand } \\
\text { Awareness }\end{array}$} & $\begin{array}{l}\text { Saya mampu mengetahui brand Xing } \\
\text { Fu Tang }\end{array}$ & 0.528 & Valid \\
\hline & $\begin{array}{l}\text { Saya mampu mengenali jenis produk } \\
\text { yang dijual Xing Fu Tang }\end{array}$ & 0.341 & Valid \\
\hline & $\begin{array}{l}\text { Saya mengetahui keberadaan merek } \\
\text { Xing Fu Tang dari promosi yang } \\
\text { dilakukannya }\end{array}$ & 0.251 & Valid \\
\hline & $\begin{array}{l}\text { Saya mampu mengingat Xing Fu } \\
\text { Tang diantara merek yang serupa }\end{array}$ & 0.298 & Valid \\
\hline & $\begin{array}{l}\text { Saya mampu mengingat varian } \\
\text { produk dari Xing Fu Tang }\end{array}$ & 0.237 & Valid \\
\hline & $\begin{array}{l}\text { Saya mampu mengenal ciri khas dari } \\
\text { merek Xing Fu Tang. }\end{array}$ & 0.280 & Valid \\
\hline & $\begin{array}{l}\text { Xing Fu Tang merupakan produk } \\
\text { yang mudah diingat oleh saya. }\end{array}$ & 0.336 & Valid \\
\hline & $\begin{array}{l}\text { Xing Fu Tang muncul dibenak saya } \\
\text { saat pertama kali saat ditanya } \\
\text { spontan mengenai produk serupa }\end{array}$ & 0.281 & Valid \\
\hline \multirow{11}{*}{$\begin{array}{l}\text { Keputusan } \\
\text { Pembelian }\end{array}$} & $\begin{array}{l}\text { Saya merasa promosi yang dilakukan } \\
\text { Xing Fu Tang sesuai dengan } \\
\text { keinginan. }\end{array}$ & 0.359 & Valid \\
\hline & $\begin{array}{l}\text { Saya merasa produk Xing Fu Tang } \\
\text { sesuai dengan keinginan }\end{array}$ & 0.226 & Valid \\
\hline & $\begin{array}{l}\text { Saya mencari informasi mengenai } \\
\text { produk Xing Fu Tang yang akan } \\
\text { dibeli. }\end{array}$ & 0.324 & Valid \\
\hline & $\begin{array}{l}\text { Saya mendapat informasi Xing Fu } \\
\text { Tang dari berbagai media. }\end{array}$ & 0.287 & Valid \\
\hline & $\begin{array}{l}\text { Saya memilih Xing Fu Tang sebagai } \\
\text { alternatif dari merek serupa. }\end{array}$ & 0.244 & Valid \\
\hline & $\begin{array}{l}\text { Saya memilih Xing Fu Tang karena } \\
\text { promosi yang dilakukannya }\end{array}$ & 0.353 & Valid \\
\hline & $\begin{array}{l}\text { Saya memilih Xing Fu Tang sebagai } \\
\text { produk yang dibeli }\end{array}$ & 0.294 & Valid \\
\hline & $\begin{array}{l}\text { Saya memilih Xing Fu Tang sebagai } \\
\text { produk yang paling disukai. }\end{array}$ & 0.344 & Valid \\
\hline & $\begin{array}{l}\text { Saya yakin membeli Xing Fu Tang } \\
\text { karena mendapat rekomendasi dari } \\
\text { orang lain. }\end{array}$ & 0.266 & Valid \\
\hline & $\begin{array}{l}\text { Saya yakin membeli Xing Fu Tang } \\
\text { karena mengenal merek tersebut. }\end{array}$ & 0.240 & Valid \\
\hline & $\begin{array}{l}\text { Saya puas terhadap produk Xing Fu } \\
\text { Tang. }\end{array}$ & 0.358 & Valid \\
\hline
\end{tabular}




\begin{tabular}{lll}
\hline $\begin{array}{l}\text { Saya memiliki keinginan untuk } \\
\text { melakukan pembelian ulang Xing Fu } \\
\text { Tang }\end{array}$ & 0.327 & Valid \\
\hline
\end{tabular}

Data primer, hasil pengolahan data SPSS

Adanya uji reliabilitas dalam penelitian ini bertujuan untuk diketahuinya seberapa besar hasil dari pengukuran tetap stabil atau konsisten, jika dilakukannya pengukuran sebanyak dua atau lebih pada gejala yang sama dengan menggunakan alat ukur yang sama (Siregar 2013: 55). Berdasarkan rumus Cronbach's Alpha, jika nilai Alpha $(\alpha)$ melebihi 0,6 maka butir instrumen yang berkaitan reliabel dan jika nilai Alpha $(\alpha)$ kurang dari 0,6 maka butir instrumen yang berkaitan tidak reliabel (Ghozali, 2011: 46).

Tabel 2. Uji Reliabilitas

\begin{tabular}{lcl}
\hline \multicolumn{1}{c}{ Variabel } & Cronbach's Alpha & Keterangan \\
\hline Word Of Mouth & 0.701 & Reliable \\
\hline Brand Awareness & 0.620 & Reliable \\
\hline Keputusan Pembelian & 0.667 & Reliable \\
\hline
\end{tabular}

Data primer, hasil pengolahan data SPSS

Tabel 3 Hasil Pengujian Hipotesis

\begin{tabular}{cccccc}
\hline Hipotesis & Path & $\begin{array}{c}\text { Standardized } \\
\text { Solution }\end{array}$ & $\begin{array}{c}T \\
\text { Values }\end{array}$ & $\begin{array}{c}T \\
\text { Tabel }\end{array}$ & Keterangan \\
\hline \multirow{2}{*}{$\mathrm{H}_{1}$} & Word Of Mouth $\left(\mathrm{X}_{1}\right)$ & & & & \\
& & 0.37 & 2.11 & 1.96 & Supported \\
& Keputusan Pembelian (Y) & & & & \\
\hline \multirow{2}{*}{$\mathrm{H}_{2}$} & Brand Awareness $\left(\mathrm{X}_{2}\right)$ & & & & \\
& $\boldsymbol{Z}$ & 0.44 & 2.38 & 1.96 & Supported \\
& Keputusan Pembelian (Y) & & & & \\
\hline
\end{tabular}

Sumber: Data primer, hasil pengolahan data SPSS

\section{Diskusi}

Menurut hasil yang diterima dari tabel 3 hasil dari pengujian hipotesis dilakukan, diketahui bahwa word of mouth memberikan pengaruh terhadap keputusan pembelian. Semakin besar word of mouth yang ada akan menimbulkan keputusan pembelian pada masyarakat. hasil penelitian ini mendukung penelitian yang dilakukan sebelumnya oleh Nugraha (2015) bahwa word of mouth memiliki pengaruh terhadap keputusan pembelian pada Cafe Roti Gempol dan Kopi Anjis.

Penelitian ini menjelaskan bahwa brand awareness memberikan pengaruh yang lebih besar pada keputusan pembelian yang dilakukan oleh konsumen. Pada penelitian ini menjelaskan bahwa semakin besar kesadaran merek yang ada, maka juga akan meningkatnya tingkat keputusan pembelian konsumen. Oleh sebab itu, untuk tetap membangun dan mempengaruhi keputusan pembelian konsumen, Xing Fu Tang harus meningkatkan lagi kesadaran merek di masyarakat. 
Jessica Tee, Rezi Erdiansyah, Sisca Aulia: Pengaruh Word of Mouth dan Brand Awareness terhadap Keputusan Pembelian Xing Fu Tang di Indonesia

Penelitian ini memiliki hasil yang juga mendukung penelitian sebelumnya yang dilakukan oleh Billy (2017) bahwa brand awareness berpengaruh terhadap keputusan pembelian sepatu Nike (studi pada pengunjung di Mall Central Park).

\section{Simpulan}

Dari penelitian yang dilakukan, penulis dapat memberikan beberapa kesimpulan. Kesimpulannya adalah sebagai berikut:

1. Word Of Mouth memiliki pengaruh positif dan signifikan terhadap keputusan pembelian di Xing Fu Tang.

2. Brand Awareness memiliki pengaruh positif dan signifikan terhadap keputusan pembelian di Xing Fu Tang.

\section{Ucapan Terima Kasih}

Ucapan terima kasih dari penulis kepada para pihak yang turut berkontribusi, memberikan dukungan, dan membantu dalam hal apapun hingga selesainya penelitian ini.

\section{Daftar Pustaka}

Billy Hermawan. (2017), Pengaruh Brand Awareness dan Brand Image terhadap keputusan pembelian sepatu Nike. Jurnal Proliga. 1. 152-157.

Detik.com, 24 September 2019, (https://m.detik.com/food/resto-dan-kafe/d4592367/xing-fu-tang-antre-2-jam-untuk-cicipi-brown-sugar-boba-milk)

Ghozali, Imam. (2011). Aplikasi Analisis Multivariate dengan Program SPSS. Semarang: Badan Penerbit Universitas Diponegoro.

Kiki Joesyiana. (2018). Pengaruh Word Of Mouth Terhadap Keputusan Pembelian Konsumen Pada Media Online Shop Shopee Di Pekanbaru. Jurnal Valuta. 4. 71-85.

Kotler, Amstrong. (2002). Manajemen Pemasaran. Jakarta: Prenhallindo.

Kotler, Amstrong. (2009). Prinsip-prinsip pemasaran. Jakarta: Erlangga.

Kotler, Amstrong. (2012). Manajemen Pemasaran. Jakarta: Erlangga.

Nisfiannoor, Muhammad. (2013). Pendekatan Statistika Modern. Jakarta: Salemba Huamanika.

Priansa, Donni Juni. (2017). Komunikasi Pemasaran Terpadu Pada Era Media Sosial. Bandung: Pustaka Setia.

Putra, D. N. (2015). Pengaruh Word of Mouth terhadap Keputusan Pembelian pada Cafe Roti Gempol dan Kopi Anjis . E-Proceeding of Management. 2. 758-763.

Rangkuti, Freedy. (2009). Strategi promosi yang kreatif. Jakarta: Gramedia Pustaka Utama.

Sernovitz. (2009). Word of Mouth Marketing. Jakarta: Gramedia Pustaka Utama.

Siregar, Syofian. (2013). Metode Penelitian Kuantitatif. Jakarta: PT Fajar Interpratama Mandiri.

Sugiyono. (2016). Metode Penelitian Kuantitatif, Kualitatif dan R\&D. Bandung: Alfabeta. 